RUNNING HEAD: Placement Verbs in L1 and L2 Danish and Spanish

\title{
Semantic Categorization of Placement Verbs in L1 and L2 Danish and Spanish
}

\author{
Teresa Cadierno, ${ }^{\mathrm{a}}$ Iraide Ibarretxe-Antuñano, ${ }^{\mathrm{b}}$ and Alberto Hijazo-Gascón ${ }^{\mathrm{c}}$ \\ ${ }^{a}$ University of Southern Denmark, ${ }^{b}$ University of Zaragoza, and ${ }^{\mathrm{c}}$ University of East Anglia
}

This study investigates sematic categorization of the meaning of placement verbs by Danish and Spanish native speakers and two groups of intermediate second language (L2) learners (Danish learners of L2 Spanish and Spanish learners of L2 Danish). Participants described 31 video clips picturing different types of placement events. Cluster analyses revealed considerable differences in the semantic categorization of these events in Danish and Spanish as well as learning difficulties for the two learner groups. When Danish and Spanish differ in the number and nature of semantic distinctions, L2 verb meaning reconstruction becomes challenging when moving from a more to less complex system and vice versa. Both learner groups used non-caused motion verbs, overgeneralized given placement verbs, and tended to use L2 verbs haphazardly.

\section{Keywords : semantic categorization; placement; Danish; Spanish}

\section{Author Note}

This project has been financed by the Velux Foundation and by the Spanish Government (MovEs, FFI2013-45553-C3-1-P). We would like to thank Thomas Nielsen for his help in data transcribing and coding, Toker Doganoglu and Isabel Casas for their help with the statistical analyses of the data, as 
well as the reviewers of this manuscript and Lourdes Ortega for their insightful comments. The elicitation instruments used for the study can be accessed by readers in the IRIS digital repository (http://www.iris-database.org).

Correspondence concerning this article should be addressed to: University of Southern Denmark, Department of Language and Communication, Campusvej 55, Odense, 5230, Denmark. Email: cadierno@sdu.dk

\section{Introduction}

Crosslinguistic research on semantic categorization has shown that languages differ widely in how they partition the world. This has been shown for domains such as color, emotions, artifacts, and topological relations (e.g., for recent reviews see Evans, 2011; Malt \& Majid, 2013). Recently, research targeting semantic typology has turned its attention to event categorization, that is, the linguistic encoding of everyday events, such as carrying events (e.g., Bowerman, 2005; Saji et al., 2011), motion events (e.g., Malt et al., 2008, 2014; Slobin, Ibarretxe-Antuñano, Kopecka, \& Majid, 2014) and cutting and breaking events (Majid, Gullberg, van Staden, \& Bowerman, 2007; Majid, Boster, \& Bowerman, 2008). The results of these studies have revealed crosslinguistic differences in the number of semantic categories that are established and in their exact boundaries (i.e., how the events are grouped together). For example, in a study with speakers of closely related languages, Majid et al. (2007) found that whereas English native speakers (NSs) group chopping and cutting events together, German, Dutch, and Swedish NSs group chopping events together with breaking events such as smashing. One type of event that has received a great deal of attention lately is that of placement events, a type of caused motion event where typically an agent causes an object to move to a specific location, as in 
John puts a cup on the table. Despite being a very specific area of research, placement events are interesting for several complementary reasons (Levinson, 2012). From a linguistic perspective, placement words are pervasive and frequent in all languages, and they are acquired quite early by children. From a neurocognitive viewpoint, placement events are related to crucial concepts such as our peripersonal space, that is, the space where one can reach and usually manipulate things, as well as to basic human sensory-motor patterns such as the manual grasping of objects. Therefore, as Levinson (2012, p. xiii) put it, these verbs "offer an interesting laboratory for the interaction between the basic neurocognition of reaching and placing and the corresponding linguistic description of such actions." Recent studies (e.g., Kopecka \& Narasimhan, 2012; Slobin, Bowerman, Brown, Eissenbei $\beta$, \& Narasimhan, 2011) have documented wide variation with respect to the semantic distinctions encoded in "putting" verbs across different languages. For example, whereas Dutch NSs use posture verbs (e.g., zetten "set/stand" vs. leggen "lay") that express properties of the Figure object (i.e., what is moved) and its orientation with respect to the Ground, or the location where the object is placed (Gullberg \& Narasimhan, 2010; Narasimhan \& Gullberg, 2011; Gullberg, 2011a), French speakers tend to use general caused motion verbs (e.g., mettre "put") that can apply to a wide range of scenes (e.g., Hickmann, 2007; Hickmann \& Hendriks, 2006).

These crosslinguistic differences in semantic categorization pose difficulties for adult second language (L2) learners ${ }^{1}$ (e.g., Ijaz, 1986; Malt \& Sloman, 2003; Saji \& Imai, 2013). In order to learn the specific meanings of L2 words, learners need to detect possible differences in the semantic distinctions encoded in their native language (L1) and their L2, and learn the appropriate linguistic means by which meanings are encoded in the L2 (Ellis \& Cadierno, 2009; Gullberg, 2009a). From this perspective, L2 learning entails learning to reconstruct L2 meanings or learning to categorize the world in a manner similar to which NSs of the L2 categorize the world, a process that has been described in 
the literature as learning appropriate L2 ways of thinking-for-speaking (TFS) (e.g., Cadierno, 2008) or learning to re-think for speaking (Robinson \& Ellis, 2008).

One aspect that can affect the ease or difficulty involved in L2 meaning reconstruction is whether the reconstruction process involves moving from a more complex semantic system to a less complex one, or moving in the opposite direction, namely, from a less complex system to a more complex one (Stockwell, Brown, \& Martin, 1965). Recent research into the L2 expression of placement events has started to investigate this issue in separate studies involving learners with different levels of L2 proficiency and different combinations of L1 and L2 language pairs (e.g., Gullberg, 2009a, b; 2011b; Viberg, 1998). The present investigation addresses the directionality of L2 verb meaning reconstruction in a single study by means of a bidirectional design which includes four groups of participants: two groups of NSs (i.e., NSs of Danish and Spanish) and two groups of adult L2 learners (i.e., Danish learners of L2 Spanish and Spanish learners of L2 Danish). This design, which includes two learner groups with similar levels of L2 proficiency and two languages functioning alternatively as the source and target languages, allows us to investigate in a systematic way the extent to which success in L2 meaning reconstruction differs when moving from a more general semantic system to a more specific system and in the opposite direction. Semantic categorization was investigated by means of cluster analysis, a statistical technique previously used in the semantic categorization of other types of events in L1 and L2 speakers (e.g., Jessen \& Cadierno, 2013; Majid et al., 2007).

\section{Background Literature}

\section{The Semantics of Placement Events}

Placement events are a ubiquitous part of everyday experience. All of us perform this type of action in our daily lives since childhood. Therefore, it is no wonder that placement-related linguistic items are 
found among the first words we produce in our own language. However, the question is, Do speakers of all languages describe placement events in the same way?

Some authors (e.g., Talmy, 2000) argue that the semantic elements that define and distinguish one type of event from another are shared by all humans no matter what language they speak, but that the linguistic means that each speaker can count on are constrained by his/her language. Prior linguistic research in this area (Jackendoff, 1990; Talmy, 1985; Ruppenhofer, Ellsworth, Petruck, Johnson, \& Scheffczyk, 2010) has identified a set of semantic components to describe placement events. These basic components are: Figure (what is moved), Agent (the causer of the movement), Ground (the location where an object is placed), Causation (what triggers the placement), Motion (the act of moving), and Path (the trajectory followed by the Figure). These basic components represent the core placement schemata but they might be extended to capture finer-grained distinctions and relations between these elements (see Ibarretxe-Antuñano, Cadierno, \& Hijazo-Gascón, in press), for example, to differentiate different types of Grounds (a bowl, a three-dimensional container vs. the floor, a twodimensional supporting surface) or to indicate how much force the Agent exerts on the Causation (cf. drop, dump, and throw).

\section{Placement Events in L1 and L2 Acquisition}

Empirical research into the expression of placement events has revealed crosslinguistic variation not only with respect to the lexical semantics of placement verbs, that is, which verbs are used to distinguish among different types of placement events, but also in relation to the syntax-semantic mappings, or how spatial semantic notions are distributed across elements in phrase and clause-level constructions (Kopecka and Narasimhan, 2012) and how they relate to the speech-associated gestures employed when talking about placement (Gullberg, 2011a). These crosslinguistic differences among 
adult NSs of different languages seem to be often preceded by a general process of semantic overgeneralization in speech, characterized by the initial overuse of neutral verbs (e.g., French mettre "put") or of a single posture verb (Dutch leggen "lay") (Gullberg, 2009b; Hickmann, 2007), and in gesture, with children moving from a single-component semantic system (caused motion) to an adultlike system with two components (caused motion and information about the object) (Gullberg \& Narasimhan, 2010).

In L2 acquisition, research on the expression of placement events has focused on the directionality of L2 meaning reconstruction. To our knowledge, two studies (Gullberg, 2009a; Viberg, 1998) have examined L2 placement verb meaning reconstruction when moving from a more general and less complex semantic system to a more specific and complex one, and both studies indicate that this type of transition poses a learning challenge for adult L2 learners. For example, Gullberg found that although English has cognates for Dutch posture verbs, English learners of L2 Dutch used posture verbs less frequently than Dutch speakers did. In addition, they used avoidance strategies such as the use of the Dutch general verb doen "do" and they overgeneralized the posture verb zetten "set/stand" over leggen "lay" to describe both horizontal and vertical placement. The gesture data further revealed that learners used similar gestures in their L1 and their L2. In both cases, the gestures expressed path towards the goal in contrast to the gestures used by Dutch NSs who typically incorporated Figure object information. With respect to the reconstruction of L2 placement verb meaning in cases where the learning proceeds from a more specific system to a more general one, a study reported in Gullberg (2009a, 2011b) showed that adult Dutch and German learners of L2 French produced targetlike placement verbs (e.g., mettre "put," placer "place"). However their L2 gestures revealed the influence of their L1 gestural patterns as well as an incipient restructuring towards the L2 patterns. For example, German learners tended to align path gestures with locative expressions, following the German NS 
pattern, but were nevertheless more likely to align path gestures with verbs than German NSs, thus also following the French NSs' pattern.

In sum, the results of the L2 studies conducted so far indicate that the transition from a more general and less complex semantic system to a more specific and complex one causes more learning difficulties than a transition in the other direction. Whereas the former type of transition reveals difficulties in semantic restructuring at both the verbal and gestural level, the latter type of transition reveals difficulties only at the gestural level.

\section{The Present Study}

The present investigation contributes to L2 crosslinguistic research on semantic categorization by examining both types of transitions in a single study and by incorporating two new language pairsSpanish and Danish. There are several reasons for choosing these two specific languages. One reason is related to how these languages encode semantic information for motion and caused motion events. Danish is a satellite-framed (e.g., løbe ud "run out") and a positional verb (e.g., ligge "lie," stå "stand") language whereas Spanish is a verb-framed (salir corriendo "exit running") and positional verbless language (estar "stative be") (Ameka \& Levinson, 2007; Cadierno, 2004). This complementary characterization makes them perfect candidates for the kind of bidirectional L2 acquisition study we describe here. The inter-typological analysis for these two language families is not new as Gullberg (2011a) already explored the pattern between Dutch and French; however, our study will provide the field with the necessary contrastive data to further explore the issue of intra-typological variation within genetically-similar languages. The final reason for focusing on Danish and Spanish is convenience: Our previous research on (caused) motion events (Cadierno, 2004; Ibarretxe-Antuñano, 2012) has enabled easy access to participants and resulted in good knowledge of the two languages in question both from the L1 and L2 perspectives. 
The present study addresses the following research questions:

1. What verbs do the two NS groups and the two learner groups use to describe placement events in Danish and Spanish?

2. What is the meaning of the verbs used by the two NS groups? That is, what are the semantic categories covered by the verbs that are used?

3. What is the meaning of the verbs used by the two learner groups? Are the learners' semantic categories appropriate/targetlike?

\section{Method}

\section{Participants}

There were a total of 52 participants in this study: 10 NSs of Spanish, 14 NSs of Danish, 14 adult Danish learners of L2 Spanish, and 14 adult Spanish learners of L2 Danish. The NS data was collected among university students in Spain (University of Zaragoza) and in Denmark (University of Southern Denmark). These participants can be characterized as functional monolinguals because they were not studying English or any other L2 at the time of data collection and because the only languages they used in their daily lives were Spanish and Danish, respectively (cf. Brown \& Gullberg, 2012). Neither group reported knowledge of the other language. At the time of data collection, the Danish learners of L2 Spanish were first-year students of this language at a Danish university. Their level of Spanish proficiency was between B1 and B2 levels according to the Common European Framework of Reference (CEFR, Council of Europe, 2001; for more information about this framework, see Appendix $\mathrm{S} 1$ in the Supporting Information online). Their level was tested through the use of the online test of the Cervantes Institute (http://ave.cervantes.es/prueba_nivel/default.htm), a governmental agency devoted to the teaching and promotion of the Spanish language and culture internationally. The Spanish learners 
of L2 Danish were all studying Danish at the Escuela Oficial de Idiomas (Official School of Languages) in Madrid. Their level of proficiency was also between CEFR B1 and B2 levels.

In addition to the placement tests, learners in both groups filled out a language background questionnaire in their L1s where they were asked about their exposure to Spanish and Danish, respectively, in both formal and informal settings, and were asked to self-evaluate their level of L2 proficiency in the various languages that they knew. The L1 Danish speakers had all studied Spanish in high school for three years (approximately 235 hours) and most of them had lived and studied Spanish in a Spanish-speaking country for a period ranging from two months to 1.5 years. All participants reported good knowledge of English and some of them reported some knowledge of other languages such as German and Greek. The L1 Spanish speakers had lived and studied Danish in Denmark for a period ranging from one month to four years. All the learners but one reported advanced knowledge of English and some reported some knowledge of other languages such as German, French, and Italian.

\section{Procedure}

The data for the present study consisted of individual videotaped oral description of 31 short video clips developed at the Max Planck Institute for Psycholinguistics in Nijmegen (Bowerman, Gullberg, Majid, \& Narasimhan, 2004; Kopecka \& Narashiman, 2012). Each video shows a human actor performing a caused motion event such as PUT CUP ON TABLE, POUR LIQUID INTO CONTAINER, PUT STONE INTO POCKET, and HANG ROPE OVER TREE BRANCH (the full list of 31 target motion events is shown in Appendix S2 in the Supporting Information online). The scenes vary along a series of dimensions, such as the nature and spatial configuration of the Figure and the Ground and the manner in which the Figure is moved. Although our data were collected using the full video set (61), this study focuses only on the placement subset (31 video clips). The videos were presented in three randomized orders to each group of participants. Each participant saw one video clip at a time and was asked to describe to the 
experimenter the event shown. In the case of the learners, they were told that if they did not know the name for a given object in the video, they could use words like "that" or "that thing" or could ask the experimenter. If asked, the experimenter provided the Spanish/Danish nouns for the Figure object or the Ground (e.g., Spanish taza "cup") but never for the L2 verbs required to describe the placement event in question.

\section{Data Analysis}

The oral data was transcribed and coded on the basis of the MPI guidelines for the PUT task (Bowerman et al., 2004). We conducted two types of analyses. In order to answer our first research question, we computed the mean values for verb tokens, verb types, and verb token-type ratios for each participant group. In addition, we computed Simpson's diversity index (Simpson, 1949) in order to examine the degree of consistency in speakers' oral descriptions (see Appendix S3 in the Supporting Information online for more information about this analysis). In order to answer our second and third research questions, we first created a video clip-by-verb matrix for each of the four sets of data where the frequency of occurrence of each verb per scene was specified. The resulting matrices were then analyzed by means of a hierarchical agglomerative cluster analysis with Euclidian distance and Ward linkage (see Appendix S4 in the Supporting Information online for more information about this analysis).

\section{Results}

\section{Verb Usage}

Table 1 shows the mean values for the verb tokens and types used by the four participant groups along with the type-token ratios. A Kruskal-Wallis test conducted on the mean type-token ratios revealed a significant difference between the groups, $\chi^{2}(3)=45.11, p<.0001$. The results of the post hoc analysis using Mann-Whitney tests with Bonferroni corrections showed significant differences between each L1 
NS group and its corresponding L2 learner group, that is, between L1 Spanish and L2 Spanish groups, $U=160.5, Z=-4.54, p<.0001,|r|=.58$, and between L1 Danish and L2 Danish groups, $U=139.5, Z$ $=-4.83, p<.0001,|r|=0.61$. That is, the mean type-token ratio of the L2 Spanish group was significantly smaller than that of the L1 Spanish group; likewise, the mean type-token ratio of the L2 Danish group was significantly smaller than that of the L1 Danish group. In contrast, no significant differences were found between the two learner groups (L2 Spanish and L2 Danish), $U=479.5, Z=$ $.014, p=.99,|r|=.002$, or between the two NS groups (L1 Spanish and L1 Danish), even though the significance level was borderline, $U=298.0, Z=2.60, p=.06,|r|=.33$.

\section{TABLE 1}

The next analysis targeted Simpson's Diversity Index (summarized for each group in Table 1). As shown in this table, a higher degree of consistency was found for the two NS groups in comparison to the two learner groups. A Kruskal Wallis test revealed a significant difference between the groups, $\chi 2^{2}(3)=47.34, p=.0001$. Post hoc analysis using Mann-Whitney tests with Bonferroni corrections again showed significant differences between each NS group and its corresponding L2 learner group: between L1 Spanish and L2 Spanish groups, $U=168.0, Z=4.41, p=.0001,|r|=.56$, and between L1 Danish and L2 Danish groups, $U=122.0, Z=5.05, p=.0001,|r|=.64$. No significant differences were found between the two NS groups, $U=476.0, Z=-.063, p=.95,|r|=.01$, and between the two learner groups even though the significance level was again borderline, $U=297.5, Z=2.58, p=.06,|r|=.33$. In other words, the two NS groups were significantly more consistent when describing the video clips than the two learner groups.

Figure 1 shows the verbs used by the L1 and L2 Spanish speakers. While L1 Spanish speakers used two predominant verbs, dejar "leave (in a place)" and meter "put in," the L2 Spanish speakers used a single verb more predominantly, the verb poner "put." In addition, whereas the "other" verb 
category for the L1 speakers includes the use of more specific verbs such as posar "place carefully" and derramarse "spill," the other verb category for the L2 Spanish learners included non-caused motion verbs (e.g., estar "be" and tener "have"), neologisms resulting from calques and borrowings from Danish or English such as placear, an adaptation from Danish placere "place" or English place, and a few Danish verbs (e.g., hoelde "pour" and smide "throw").

\section{FIGURE 1}

Figure 2 shows the verbs used by the L1 and L2 Danish speakers. Both the L1 and the L2 Danish speakers used the same two verbs more predominantly, namely, loegge "lay" and scette "set." Some of the other verbs were used with roughly the same frequency by the two groups of speakers (e.g., putte "put, put in" and hoenge "hang") whereas other verbs were used with different frequency. For instance, tage "take" was more frequent in the learner than in the NS data. Finally, whereas the other verb category for the L1 Danish speakers includes more specific verbs such as kaste "throw" or skubbe "push," the other verb category for the L2 Danish learners includes the use of intransitive posture verbs (e.g., ligge "lie") and other non-caused motion verbs (e.g., have "have," voere "be"). The complete list of verbs used by the four participant groups is shown in Appendix S5 in the Supporting Information online.

\section{FIGURE 2}

\section{Cluster Analysis for the Two NS Groups}

Figure 3 shows the cluster dendrogram for the L1 Spanish data. There are six well-defined clusters, representing six different semantic categories. The scenes in the first cluster are predominantly described with the verb dejar "leave (in a place)," a force-dynamic caused motion verb involving a soft type of placement. All the scenes except one (i.e., PUT APPLE INTO BOWL) depict a support relation between the Figure and the Ground. The scenes in the second cluster are predominantly described by 
the verb ponerse "put on" and they all depict dressing events (i.e., events where the moving Figure is a piece of clothing and the Ground is part of the Agent's body). The scenes in the third cluster are predominantly described with the verb poner "put" and they cover scenes depicting both support (PUT SAUCER ON TOP OF CUP) and partial containment relations (PUT CANDLE INTO CANDLE STAND and PUT FLOWER INTO HAIR-SKEWER). The two scenes in the fourth cluster are predominantly described with the verb tirar "throw." These scenes depict an Agent throwing a Figure object (e.g., a book) onto the Ground (e.g., the floor). Force dynamics and intentionality are key conceptual elements in the description of these scenes. The fifth cluster groups two scenes that are predominantly described with the pronominal verb caerse "fall" that expresses lack of intentionality on the part of the Agent in relation to the caused motion event. Finally, the sixth cluster comprises scenes described with the verb meter "put in." These scenes depict a containment relation between the Figure and the Ground. The use of this verb provides support for the status of Spanish as a V-language, as the path verb meter "put in" is used when the Figure object ends up moving inside a Ground which is a container. In addition to these well-defined clusters, there are seven scenes marked by a discontinuous line where each scene is predominantly described by means of a different verb. The use of these specific verbs depends on a series of factors. For example, scenes where the Figure is liquid or granular (POUR LIQUID INTO CONTAINER) are described by the verbs verter "pour" and derramar "spill" whereas the scene PUT POSTER ON WALL is predominantly described by pegar "stick, glue," and the scene HANG ROPE OVER TREE BRANCH, by colgar "hang."

\section{FIGURE 3}

Figure 4 shows the cluster dendrogram for the L1 Danish data. There are eight well-defined clusters. The first cluster comprises scenes that are predominantly described with the verb lagge "lay"; these scenes depict support and containment relations where the Figure object has a horizontal 
extension from the Ground or it lacks a functional base (e.g., PUT BOOK ON FLOOR, PUT PEN IN HOLE IN TREE TRUNK). The second cluster comprises scenes that are predominantly described with the verbs scette "set" and stille "set." All the scenes depict a support type of relation in which the Figure object has a vertical extension from the Ground or the Figure object has a functional base (e.g., PUT CUP ON TABLE). The third cluster covers three scenes that are predominantly described with the verb satte "set"; one of the scenes depicts a support relation where the Figure object is vertically placed (PUT PLASTIC CUP ON TABLE WITH MOUTH) whereas the other scenes portray a partial containment relation (PUT FLOWER INTO HAIR-SKEWER and PUT CANDLE INTO CANDLE STAND). The fourth cluster covers two scenes described with the verb hoenge "hang" describing events such as PUT POSTER ON WALL and HANG ROPE OVER TREE BRANCH. The fifth cluster comprises scenes that are predominantly described with the verb smide "throw" where an object is "thrown" on both a surface and into a container (e.g., TOSS BOOK ON FLOOR). The sixth and seventh clusters are respectively described with the verb stikke "stick" and putte "put, put in," and they both cover scenes that reflect a containment type of relation between the Figure and the Ground (PUT HEAD INTO BUCKET and PUT HAND INTO HOLE IN TREE). The eighth cluster is predominantly described with the verb tage "take," used for dressing events (e.g., PUT BOOT ON FOOT). Finally, there are three scenes_-marked with a discontinuous line — where each scene is predominantly described by means of a different verb (e.g., the verb hoelde "pour" for POUR LIQUID INTO CONTAINER and the verb spilde “spill” for SPILL WATER ONTO TABLE WHEN PICK UP GLASS).

\section{FIGURE 4}

The cluster analyses for the L1 Spanish and Danish data show that, with a few exceptions, the two languages differ with respect to their semantic organization. For example, the two languages coincide in the case of dressing events. The scenes PUT BOOT ON FLOOR, PUT ON COAT, and PUT HAT ON HEAD are described in each language by means of a single verb, namely, ponerse "put on" in Spanish 
and tage (på) "put on" in Danish. In the remaining categories, the semantic categorization of the two languages does not coincide. For example, in the scenes included in Figure 5, which depict a support relation between the Figure and the Ground, Spanish NSs tend to use a single verb (dejar "leave in a place") whereas Danish NSs employ two sets of verbs (loegge "lay" for horizontally placed objects or objects that lack a functional base, and satte/stille "set" for vertically placed objects or objects that have a functional base) (e.g., Gullberg \& Burenhult, 2012).

\section{FIGURE 5}

Likewise, in the scenes depicted in Figure 6, which depict a containment relation between the Figure and the Ground, Spanish NSs tend to use a single verb (meter "put in") whereas Danish NSs employed three different verbs: loegge "lay" when Figures are placed horizontally (e.g., PUT STONE INTO POT OF WATER, PUT PEN IN HOLE IN TREE TRUNK); stikke "put in, stick" when the (often pointed-shaped) Figure follows a trajectory along a path to penetrate (totally or partially) a container and the resulting relation between the placed object and the container is often one of tight-fit (e.g., PUT HEAD INTO A BUCKET, PUT HAND INTO HOLE IN TREE); and putte "put, put in," a frequent verb in speech whose use seems to be underspecified; it can be employed, for example, in cases of tight-fit and loose-fit relations (e.g., STUFF RAG INTO A CAR EXHAUST PIPE, DROP APPLE INTO BAG). Further information about the use of these verbs in Danish corpora is provided in Appendix S6 in the Supporting Information online.

\section{FIGURE 6}

Table 2 provides an overview of the Danish and Spanish semantic categories as reflected in our data. Only the most frequently used verbs for each semantic category appear in the table. The Spanish system is simpler than the Danish one, in that three different verbs are predominantly used: dejar "leave (in a place)" for support, poner "put" for partial containment, and meter "put in" for full containment. In contrast, the Danish system contains a larger variety of verbs that are used—seven 
different verbs - with some overlap in their usage. Specifically, the verb laegge "lay" was used for horizontally placed objects and full containment relations between the Figure and the Ground. The verb sæette "set" was used for support relations in the case of vertically placed object, and for scenes involving partial containment. This verb was also used, though very infrequently, for two of the scenes predominantly described by putte "put, put in," namely, STUFF RAG INTO CAR EXHAUST PIPE and PUT CELERY BUNCH INTO RECORDER CASE. In addition, the general verb putte "put, put in" was occasionally employed in the descriptions of some of the scenes depicting containment, that is, full containment, in scenes predominantly described by the verb laegge "lay" (PUT STONE INTO POT OF WATER, PUT PEN IN HOLE IN TREE TRUNK) and partial containment, in the scene PUT CANDLE INTO CANDLE STAND where the verb scette "set" was predominantly used. The remaining verbs were reduced to one single category in our data: the verb stille "set" was only employed for support relations in the case of vertically placed objects, and the verb stikke "put, stick" was mainly used for tight-fit relations.

\section{TABLE 2}

\section{Cluster Analysis for the L2 Spanish Learners}

Figure 7 illustrates the cluster dendrogram for the L2 Spanish data. In both Figures 7 and 8, the symbol -\% appears after the verb when the verb in question is the most frequently used for the description of the scenes in the cluster but its frequency of use does not reach $50 \%$ of the cases. There are three welldefined clusters in the data by the Danish learners of L2 Spanish. The common denominator of the first cluster is that there is no single verb that predominates in the description of each scene. For example, the scene TOSS BOOK ON FLOOR was described by seven different verbs, and none of them was used in at least $50 \%$ of the cases. For this reason the cluster has been named "mixed." The second cluster covers dressing scenes that were predominantly described by the verbs poner "put" and llevar "carry." The third cluster covers scenes that were predominantly described by means of the verb poner "put." 
This big cluster was used for both support and containment relations between the Figure and the Ground (e.g., PUT BOOK ON FLOOR and PUT HAND INTO HOLE IN TREE). This cluster is composed of two sub-clusters. The first of these sub-clusters included one where the verb poner "put" was employed by an average of six out of the total of 14 participants, and a mean of five other verb types were used per scene. In the second sub-cluster, there was a clearer dominance of the verb poner "put" in the description of each scene; in this sub-cluster, the verb poner was employed by an average of nine out of the total of 14 participants, and a mean of three other verb types were used. Finally, there was one scene—GIVE CUP TO SOMEONE—-that was predominantly described with the verb dar "give."

\section{FIGURE 7}

\section{Danish Learners' Restructuring of L2 Spanish Semantic Categories}

If we compare the cluster dendrograms for the L1 and L2 Spanish data (Figures 3 and 7, respectively), we can define the Danish speakers' learning task and describe their learning outcome. With respect to support relations between the Figure and the Ground, the learners needed to move from two semantic categories in their L1 (loegge "lay" for horizontally placed objects and scette/stille "set" for vertically placed objects) to one single category in their L2 (dejar "leave"). However, the verb that was predominantly used by the learners was poner "put," a verb that is not inappropriate but does not coincide with the Spanish NSs' choice. Regarding containment relations, the learners needed to move from one semantic category in their L1 (scette "set") to one category in their L2 (poner "put") in the case of partial containment, and from three semantic categories in their L1 (loegge for horizontally placed objects, stikke "put, stick" for tight-fit type of relations and putte "put, put in" for a wider range of events) to a single category in their L2 (meter "put in") in the case of full containment. The verb that was predominantly used by the learners in all cases was again poner "put." This shows that the learners do not semantically differentiate between a support and containment relation as Spanish NSs do. In 
addition, the learner group also employs the verb poner "put" for scenes where the Spanish NSs used more specific verbs such as verter "pour" and derramar "spill." Finally, regarding the description of dressing events, the learners needed to move from one semantic category in their L1 (tage på "take on") to one category in their L2 (ponerse "put on"). And again the learners' choice of verb does not coincide with that of the Spanish NSs as the verbs poner "put" and llevar "carry" were the predominant verbs used for these scenes.

\section{Cluster Analysis for the L2 Danish Learners}

Figure 8 shows the cluster dendrogram for the L2 Danish data. There are eight well-defined clusters in this data, the same number that were found in the L1 Danish data. The make-up of the clusters, however, does not coincide with the L1 clusters. The first cluster covers scenes that are predominantly described by the verb loegge "lay" and involves events where there is a support relation between the Figure and the Ground. (e.g., PUT BOOK ON FLOOR, PUT BOX UP ON SHELF). The second cluster involves scenes that depict dressing events predominantly described by means of the verb tage "take." The third cluster covers scenes that depict partial and full containment relations between the Figure and the Ground (e.g., PUT CANDLE INTO CANDLE STAND, STUFF RAG INTO CAR EXHAUST PIPE). This cluster is predominantly described by means of the verb tage "take" but this verb was employed in less than 50\% of the cases, with an average of five different verbs used for each scene. The fourth cluster was used to describe two scenes with suspended objects (PUT POSTER ON WALL and HANG ROPE OVER TREE BRANCH) by means of the predominant verb hoenge "hang." The fifth cluster covers three scenes that depict both support and containment relations between the Figure and the Ground (TOSS BOOK ON FLOOR, POUR LIQUID INTO CONTAINER, FLIP BLOCK OFF NOTEPAD INTO BOWL). These scenes were mainly described with the verbs putte "put, put in" and loegge "lay" but these verbs were again not used in at least 50\% of the cases. The sixth cluster is named "mixed" because there was no predominant verb used in the 
description of each of the two scenes. The seventh cluster, which comprises scenes depicting a support relation between the Figure and the Ground, was described by the verbs scette "set" and stille "set" even though the use of these verbs did not reach $50 \%$ of the cases. The eighth and last cluster mainly covers scenes that depict partial and full containment configurations (e.g., PUT FLOWER INTO HAIR-SKEWER, PUT HEAD INTO BUCKET). This cluster was predominantly described by means of the verb sœette "set," which was used in less than $50 \%$ of the cases. In three of the scenes (PUT STONE INTO POT OF WATER, PUT SAUCER ON TOP OF CUP, and PUT PEN IN HOLE IN TREE TRUNK) learners used both scette "set" and lagge "lay" with similar frequency. Finally, the scene GIVE CUP TO SOMEONE was predominantly described by means of the verb give "give" whereas the scene DROP BOOK ACCIDENTALLY ON FLOOR was predominantly described by the verb falde "fall" although the use of this verb did not reach $50 \%$ of the cases.

\section{FIGURE 8}

\section{Spanish Learners' Restructuring of L2 Danish Semantic Categories}

If we compare the cluster dendrograms for the L1 and L2 Danish data (Figures 4 and 8, respectively), we can see that with respect to support relations between the Figure and the Ground, the learners needed to move from a single semantic category in their L1 (dejar "leave") to two categories in their L2 (lagge for horizontally placed objects and scette/stille for vertically placed objects). In the description of the video clips, the learners appropriately used the verb laegge "lay" for scenes such as PUT BOOK ON FLOOR and PUT BANANA ON TABLE WITH LONG TONGS but they also used this verb inappropriately for scenes where the Figure object is placed vertically in relation to the Ground (e.g., PUT BOX UP ON SHELF). In addition, they used the verbs scette "set" and stille "put vertically" appropriately for scenes such as PUT SAUCER ON TOP OF CUP. 
Regarding partial containment configurations, the learners needed to move from one semantic category in their L1 (poner "put") to one category in their L2 (scette "set"), and they were able to use this verb appropriately for the scene PUT FLOWER INTO HAIR-SKEWER but they also employed the verb tage "take" for partial containment, as in PUT CANDLE INTO CANDLE STAND. With respect to full containment configurations, the leaners needed to move from one category in their L1 (meter "put in") to three categories in their L2 (lagge "lay," stikke "stick," and putte "put, put in"). Some learners appropriately used the verb laegge "lay" for horizontally-placed objects (e.g., PUT STONE INTO POT OF WATER, PUT PEN IN HOLE IN TREE TRUNK) but others employed scette "set" for this type of scenes, a choice that was not present in the L1 Danish NS data. In addition, leaners inappropriately used the verbs scette "set" and loegge "lay" for the scenes where NSs used the verb stikke "stick" (e.g., PUT HEAD INTO BUCKET, PUT HAND INTO HOLE IN TREE). With respect to the verb putte "put, put in," some learners used this verb appropriately for the scenes PUT CELERY BUNCH INTO RECORDER CASE and STUFF RAG INTO CAR EXHAUST PIPE but others employed tage "take" in the description of these scenes, a choice that was again not employed by Danish NSs. Finally, with respect to the dressing events, the learners needed to move from one category in their L1 (ponerse "put on") to one category in their L2 (tage på) and they were able to appropriately employ this verb for this type of events.

\section{Item Analysis}

Given that learners tended to use the L2 placement verbs differently than NSs, we conducted an item analysis that examined whether learners knew the core meaning of the L2 verbs or whether they used different verbs for different scenes in a haphazard way. This was investigated by comparing Simpson's Diversity Index values, which estimate the degree of name agreement, for each scene by the L1 and the L2 speakers. These analyses are summarized in Figure 9; in this figure, the top plot shows the Spanish L1 and L2 data whereas the bottom plot illustrates the Danish L1 and L2 data. Both plots show the 
values of D for each scene, filled circles for NSs and unfilled circles for L2 learners. The circles are connected by a line which represents the distance between the two values of $\mathrm{D}$ for each scene. Thus, longer lines indicate larger discrepancies between the D values of NSs and L2 learners. Segments are displayed by dotted lines when learners' $\mathrm{D}$ is the smallest and continuous lines otherwise. As shown in the figure, most segments are dotted lines,implying that the L2 learners used more different verbs to describe each scene than the NSs. The horizontal dash line represents the $90^{\text {th }}$ percentile of the NS D values. In the case of the Spanish data, this corresponds to scenes numbered 002, 004, 009, 023, 024, 025, 026 and 033. These are the scenes where Spanish NSs' performance was most consistent, that is, where they used the smallest number of verbs and where the distance with respect to the learners' performance was largest. Similarly, for Danish native speakers, scenes with a D value above the $90^{\text {th }}$ percentile are scenes numbered 007, 020,025, and 033. The results of this analysis indicate that those scenes where NSs achieved a higher level of consistency in their verb use did not elicit a more consistent verb pattern use on the part of the learners. In fact, Pearson's correlation values for the D values of the L1 and L2 groups were .04 $(p=.80)$ and $.20(p=.37)$ for the L1-L2 Spanish and L1-L2 Danish data, respectively. As these correlations were not statistically different from zero, we conclude that both learner groups used different verbs for various scenes in a haphazard manner. Appendix S7 in the Supporting Information online shows the full list of verbs used by the participant groups for each video clip within each cluster.

\section{FIGURE 9}

\section{Discussion}

The main aim of this study was to examine the semantic categorization of placement verbs in two groups of NSs (NSs of Danish and Spanish) and two groups of intermediate adult L2 learners (Danish learners of L2 Spanish and Spanish learners of L2 Danish). Specifically, we addressed three research 
questions: (1) What verbs do the two NS groups and the two learner groups use to describe placement events in Danish and Spanish?; (2) What is the meaning of the verbs used by the NS groups? That is, what are the semantic categories covered by the verbs that are used?; and (3) What is the meaning of the verbs used by the two learner groups? Are the learners' semantic categories appropriate/targetlike? Verb usage in Danish and Spanish

Regarding the first research question, verb usage by learners and their corresponding NS groups differed, first, with respect to the frequency with which particular verbs were employed. This is particularly evident for the L2 Spanish learner group, which clearly overgeneralized one generalpurpose verb (poner "put") for the description of many placement events, whereas the L1 Spanish NS predominantly employed two different verbs: dejar "leave (in a place)" and meter "put in.". Second, the NS-L2 groups differed in the use of non-caused motion verbs, which were not found in the NS data (e.g., Spanish estar "be [stative]," Danish have "have"), a phenomenon that has also been previously documented in the L2 expression of placement events (e.g., Gullberg, 2009a ; Viberg, 1998). Third, the NS-L2 groups also differed in the amount of verb types employed. On average the two learner groups used fewer verb types than their corresponding NS groups. This means that each individual learner tended to use a more restricted repertoire of verbs in the description of the placement events than the NSs of the corresponding target language. In the case of the L2 Danish learner group, the lack of knowledge of the appropriate L2 placement verbs was evidenced by their use of neologisms (e.g., placear "place") and verbs directly taken from their L1 Danish in their Spanish descriptions (e.g., hoelde "pour"). Finally, the NS-L2 groups differed in the consistency in verb use. As shown by the values of Simpson's Diversity Index, both learner groups were significantly less consistent than the corresponding target NS groups with respect to verbs that were used. This finding partly parallels the 
one observed in Jessen and Cadierno (2013) where German learners of L2 Danish were less consistent than Danish NSs in their use intransitive motion verbs.

Semantic categorization in L1 Danish and L1 Spanish With respect to the second research question, the results of this study revealed that even though NSs of Danish and Spanish did not differ with respect to overall verb type-token frequency and lexical consistency, the semantics of the verbs that they used did differ, thus suggesting different ways of categorizing placement events crosslinguistically. The two languages differed with respect to the number of semantic categories and the nature of the semantic distinctions that were made. Spanish NSs made a categorical distinction between events involving a support or a containment relation between the Figure and the Ground by consistently using the verb dejar "leave (in a place)" for the former type of events and meter "put in" for the latter. In contrast, Danish NSs made a finer semantic categorization within each of the two types of placement events. For support, Danish makes a distinction between events in which the Figure is horizontally or vertically-placed with respect to the Ground, a pattern observed in other Germanic languages (e.g., Viberg, 1998, and Gullberg \& Burenhult, 2012, for Swedish; Narasimhan \& Gullberg, 2011, Gullberg, 2009a, 2011a, b, and Gullberg \& Narasimhan, 2010, for Dutch). Regarding full containment, Spanish NSs tended to predominantly use one verb (meter "put in") whereas Danish NSs used three different verbs for the same scenes (logge "lay," stikke "stick," and putte "put, put in," in order to describe scenes where the horizontal dimension of the placed object is dominant, scenes with a tight-fit relation between the Figure and the Ground, and a wider spectrum of scenes involving different configurations, respectively.

These findings replicate, on the one hand, what has been previously found in motion event descriptions in Danish and Spanish (see Cadierno, 2004). Danish, as a satellite-framed language, relies on a larger set of linguistic resources to express the way in which an object is placed, in comparison 
with Spanish, a verb-framed language. However, on the other hand, this study also demonstrates that the two languages carve up the semantic space of placement events in different ways. Danish focuses on the vertical/horizontal position of the Figure (loegge "lay," scette "set"/stille "put vertically") whereas Spanish pays more attention to the spatial topological configuration and the dynamic relationship established between the Figure and the Ground. Dejar "leave (in a place)" is used for support scenes where there is no much intentionality on the part of the Agent; poner "put," despite being the general basic-level verb, is consistently used for partial containment; and meter "put in" is preferred for full containments. In other words, this study reveals that under-specified lexical encoding does not preclude an event representation to take other information into account. In fact, Spanish (and other Romance languages) features quite a productive group of verbs that focus on the nature of Figure denominals such as tapar "put a lid on" (tapa "lid"), taponar "put a plug on" (tapón "plug") and on the type of Ground, including verter "pour" and derramar "spill" for liquids and granular substances.

The particular verb choices in this data set might be dependent on the elicitation stimuli but if our data are compared to other similar languages (same genetic family and same lexicalization pattern), both interesting similarities and differences arise. As far as Danish is concerned, other studies on Dutch, German, and Swedish, all positional verb and satellite-framed languages, report parallel results. Gullberg (2011a) finds that Dutch speakers pervasively choose to describe placement events with a set a three positional verbs zetten "set/stand (vertical)," leggen "lay (horizontal)," and hangen "hang." The same tendency is found for Swedish and German (verbs), this time using the same stimuli and procedure (see Gullberg \& Burenhult, 2012). However, to belong to the same language family does not necessarily encompass similar descriptive strategies. Gullberg (2011a) reports that in French, a positional-less and verb-framed language, one single verb (mettre "put") stands out above the other verb types, and so does Berthele (2012) for Sursilvan. Speakers of this Romansch variety 
systematically use the verb metter "to put." These verbs are the equivalent of Spanish poner "put," that is, general placement verbs. However, the usage of this general verb in French, Sursilvan Romansch, and Spanish has a different distribution. Although they the Spanish verb poner "put" can be used in all contexts, Spanish speakers seem to choose a wider array of verbs depending on other semantic information (support, containment, force-dynamics). This result is crucial for semantic typology because it motivates further research on intra-typological variation. Other studies on motion events have already argued for this variation within lexicalization patterns as well as within genetic families (see Hijazo-Gascón \& Ibarretxe-Antuñano, 2013, for Romance languages, and Ibarretxe-Antuñano, 2004, 2009, for Basque and other languages, respectively); therefore, the next step should be to carry out larger-scale and finer-grained analyses within genetically-similar languages.

\section{Semantic categorization in L2 Danish and L2 Spanish}

Regarding the third research question, the results of the present study showed that intermediate learners of L2 Spanish and L2 Danish had difficulties in recategorizing the L2 semantic space of placement events. In other words, at this level of L2 proficiency, learning difficulties remain for learners who generally start off with a less complex system and need to acquire a more complex one (Spanish learners of L2 Danish) and for learners who generally start off with a more complex system and need to move to a less complex one (Danish learners of L2 Spanish). This result contrasts with previous research in the L2 expression of placement events where learning difficulties in speech had only been found for learners moving from a less to a more complex system (Gullberg, 2009a, 2011b; Viberg, 1998). This discrepancy in the results may be explained by the nature of the designs adopted in previous studies vis-à-vis ours. Whereas previous research has examined the issue of learning directionality in separate studies involving different language pairs and learners with different language backgrounds and levels of L2 proficiency, the design adopted in the present study has allowed us to 
make a direct comparison of the type of transition involved in L2 learning by keeping constant both the source and target languages and the learners' level of L2 proficiency.

The nature of the learning difficulties faced by both learner groups becomes clearer when we examine the semantic categorization of different types of placement events in more detail. When the two languages vary with respect to the number of semantic categories and thus the nature of semantic distinctions, the process of L2 meaning reconstruction becomes difficult irrespective of the nature of the transition that has to be made (i.e., from a more to a less complex system or from a less to a more complex system). This is the case for placement events where there is a support and full containment relation between the Figure and the Ground. Spanish learners of L2 Danish had difficulties in moving from one linguistic category in their L1 Spanish (dejar "leave [in a place]") to two categories in their L2 Danish (loegge "lay" and sætte/stille "put vertically") in the expression of support configurations. For full containment spatial configurations, these learners again showed difficulties in moving from a single category in their L1 (meter "put in") to three categories in their L2 (logge "lay," stikke "stick," and putte "put, put in"). The learning task faced by the Danish learners of L2 Spanish when describing support and full containment configurations turned out to be problematic as well. Even though the transition in both cases involved moving from a less complex to a more complex system, these learners failed to make the L2 appropriate semantic distinction between support and full containment (i.e., dejar "leave" and meter "put in") by using the verb poner "put" for both types of placement events. ${ }^{2}$

In contrast, when the two languages have the same number of semantic categories for the description of a particular placement event, the process of L2 meaning reconstruction seems to be slightly less difficult, at least for one of our learner groups. The descriptions provided by the L2 Danish group for events involving partial containment configurations (coded in Spanish and Danish by the verbs poner "put" and scette "set") and dressing events (coded in Spanish and Danish by the verbs 
ponerse "put on" and tage (pa) "put on") were generally appropriate. In the case of the L2 Spanish group, however, the picture is more complex. These learners tended to describe partial containment configurations the former by means of the general purpose verb poner "put" and dressing events the latter by means of again poner "put" as well as the intransitive verb llevar "carry." In the first type of events, the learners' performance coincides with that of Spanish NSs. In the second type of events, there is no agreement but the choice of the verb poner "put" results in an approximation to the NS use of the pronominal verb ponerse "put on." In both cases, the appropriate or targetlike use of the verb poner "put" seems to result from an overall tendency to overgeneralize this verb to all types of placement events.

The above findings point to an important finding in our study, namely, that even when L2 learners used the same verbs as the L1 speakers, they did not use them in the same way. Both learner groups tended to overgeneralize one or two verbs in their description of scenes that were described by the corresponding NS group via the use of a wider array of verbs. As noted above, the verb that was overgeneralized by the L2 Spanish group is the general-purpose verb poner "put." In the case of the L2 Danish group, two verbs were mostly generalized: laegge "lay," which was overused to cover vertical placement in support type of spatial relations and tight-fit spatial relations in cases of full containment, and scette "set," which was overused to express spatial relations involving full containment. The overgeneralization of a general-purpose verb or a given posture verb to placement events has been documented in previous L1 and L2 research. For example, French children tended to use the verb mettre "put" before they were able to use more specific placement verbs (e.g., Hickmann \& Hendriks, 2006; Hickmann, 2007), and Dutch children tended to initially overuse the verb leggen "lay" over zetten "set/stand" for vertically positioned objects (Gullberg \& Narasimhan, 2010). In L2 acquisition, Viberg (1998) documented the overuse of Swedish lägga "lay" in child L2 learners of Swedish with 
non-Germanic L1s, and Gullberg (2009a) found that English learners of L2 Dutch overgeneralized the verb zetten "set/stand" over loeggen "lay."

What processes can explain the overgeneralization of these verbs in both learner groups? One of the explanations provided by previous research is "transfer to nowhere" (Kellerman, 1995). For example, Gullberg (2009a) explained the overextension of zetten "set/stand" as reflecting this principle in the sense that the English learners of L2 Dutch looked for ways to express the L1-typical general caused motion meaning. In the case of our L2 Spanish learners, the overextension of the Spanish verb poner "put" cannot be attributed to the transfer to nowhere principle as the learners do (at least partially) make this semantic distinction through the use of different verbs in their L1 Danish. A more plausible explanation may be the influence of the English verb put as Danish learners of L2 Spanish all reported having an advanced level of English knowledge. Two additional arguments for this explanation are the fact that English has a strong presence in Danish daily life in the form of TV programs and films which are always broadcast in the original language, thus leading to potential massive exposure to this verb in the input, and the fact that the verb forms poner and put have a certain phonological similarity and thus can be rather transparent in their form.

In the case of L2 Danish learners, the overgeneralization of the verbs laegge "lay" and saette "set" may be due to factors such as semantic transparency and form-function contingency (e.g., Ellis, 2008). The core meaning of lagge "lay" is that of horizontal placement but as this verb is used to code horizontality in both support and full containment spatial relations, its meaning may not turn out to be very transparent for Spanish learners. The verb satte "set" can likewise be used for both partial and full containment (see examples in Appendix S6 in the Supporting Information online), and like its Dutch counterpart zetten (Gullberg, 2009a), it can be used in non-placement contexts such as scette prisen "set the price." In addition, depending on the particle that follows, satte can have various meanings, for 
example, scette sammen "set together, assemble," sæette på "fix, fix on." All this points to sctte as a rather unreliable form in terms of form-function mapping.

An interesting question is whether the two groups of learners, despite their tendency to overgeneralize one or two verbs, have a clear understanding of L2 verbs' core meanings. In other words, did the learners use L2 verbs more appropriately in those scenes that were more consistently described by NSs? The answer is no. As reflected in the results of the item analysis, the learners' verb use was not more appropriate in those scenes where NSs achieved a larger degree of lexical consistency, thus suggesting a tendency for learners to use L2 verbs in a haphazard manner. Finally, one note of caution in the interpretation of our findings: Both learner groups knew other foreign languages, in addition to Spanish and Danish. Therefore we cannot be sure that the patterns we observe in our data can only be explained on the basis of learners' L1. The role of English influence has to be considered as all our participants but one in both learner groups reported an advanced level of English (the remaining learner reported an intermediate level). Some were also proficient in other languages (e.g., German and Greek in the case of some Danish participants; French, German, and Italian in the case of Spanish participants). ${ }^{3}$ As previously mentioned, English is much more present in daily life in Denmark (in mass media, films, etc.) than in Spain, where there is a larger number of cultural products produced in Spanish-speaking countries and where most audiovisual cultural products are dubbed. Therefore, it can be argued that Danish participants were much more exposed to English from an early age. This might have had an impact on the Spanish L2 performance by Danish NSs. In the case of the Spanish speakers, however, we cannot completely rule out the influence of English on their L2 Danish performance. Although their exposure to English was presumably inferior to that of the Danish speakers, they all acquired Danish after English. As Brown and Gullberg (2010) show with Japanese non-monolingual speakers of English, "the use of one's L1 can be subtly altered with even intermediate 
proficiency in an L2" (p. 281). This is an interesting issue for further debate that needs to be clarified in future studies as the semantic categorization of English placement events is different from both Danish and Spanish.

\section{Conclusion}

The results of the present study point to two main findings. First, there are crucial crosslinguistic differences in the way in which Danish and Spanish NSs semantically categorize placement events. The findings from Danish in relation to previous work conducted on Swedish (Gullberg \& Burenhult, 2012) point to crucial intra-typological differences within genetically-close languages. Secondly, L2 learning difficulties remain at the intermediate level of L2 proficiency for learners moving from a more complex semantic system to a less complex one (e.g., Danish learners of L2 Spanish) and from a less complex system to a more complex one (e.g., Spanish learners of L2 Danish). More specifically, when the learners' L1 and L2 differ in terms of the number of semantic categories for the expression of particular types of placement events and thus the nature of semantic distinctions, learning difficulties are present for learners engaged in both types of transition. These difficulties can be observed in the tendency found in both groups to (a) use placement verbs that were not employed by the corresponding NS group; (b) overgeneralize L2 placement verbs that were used by the corresponding NS group, a tendency that was more pronounced in the case of the L2 Spanish data but was also present in the L2 Danish data; and (c) use L2 placement verbs in a haphazard manner. The results of the present study thus indicate that both learner groups faced difficulties when learning alternative ways of thinking for speaking (Cadierno, 2004, 2008) or learning to re-think for speaking (Robinson \& Ellis, 2008). That is, they failed to make target language semantic distinctions and they failed to use the appropriate L2 verbs to express those distinctions. 
The results of this study have pedagogical implications. The learning difficulties documented in the present investigation with learners in foreign language contexts point to the need of raising learners' awareness to this semantic domain which is not traditionally covered in foreign language classrooms. Pedagogical interventions could be designed to help learners learn to re-think for speaking in the semantic domain of placement and thus become more targetlike when describing this type of events. Interventions should point to the similarities and differences in the semantic categorization of placement events in the learners' L1 and L2 and then focus on those that are known to be especially problematic for the L2 learners in question. Video clips such as the ones used in the present study and activities involving the movement of actual objects could be used in L2 classrooms to help learners recategorize this semantic domain. A more detailed discussion of potential pedagogical implications of this research can be found in Hijazo-Gascón, Cadierno, and Ibarretxe-Antuñano (forthcoming).

Finally, the present study is limited in that there were few informants in each group and the sampling method used was non-random. Future studies should include larger and if possible randomlyselected samples in order to increase the external validity of this type of investigation. In addition, future work could examine the L2 recategorization in the semantic domain of placement from a developmental perspective by means of cross-sectional designs that include learners with different levels of L2 proficiency or longitudinal case studies where individual learners' performance is followed over time. Replications of the present study with other language pairs could also be performed in order to investigate in more detail the role of possible inter- and intra-typological differences in the L2 semantic recategorization of placement events. Finally, the role of English in the semantic recategorization process is one of the challenges for research targeting other second or foreign languages, and it thus needs to be taken into account in more systematic ways in future research. 


\section{Notes}

1 We use the term "second language (L2)" as a cover term for learners acquiring languages other than the first, whether this is a second, a third, or a fourth language.

2 We must stress that the verb poner "put" can be used on some occasions in Spanish to express placement events where both support and full containment types of relations are expressed. However, this verb was not the verb that was preferred by our NS group to code these particular sets of scenes.

3 Only few speakers reported basic knowledge of other languages, such as Japanese, Portuguese, or Dutch.

\section{References}

Ameka, F. K., \& Levinson, S. C. (Eds.). (2007). The typology and semantics of locative predication: Posturals, positionals and other beasts [Special Issue]. Linguistics, 45(5). doi:10.1515/LING.2007.025

Berthele, R. (2012). On the use of PUT verbs by multilingual speakers of Romansch. In A. Kopecka \& B. Narasimhan (Eds.), Events of putting and taking: A crosslinguistic perspective (pp. 145-165). Amsterdam: John Benjamins.

Bowerman, M. (2005). Why can't you "open" a nut or "break" a cooked noodle? Learning covert object categories in action word meanings. In L. Gershkoff-Stowe \& D. H. Rakison (Eds.), Building object categories in developmental time (pp. 209-243). Mahwah, NJ: Lawrence Erlbaum. 
Bowerman, M., Gullberg, M., Majid, A., \& Narasimhan, B. (2004). Put project: The cross-linguistic encoding of placement events. In A Majid (Ed.), Field manual volume 9 (pp. 10-24). Nijmegen: Max Planck Institute for Psycholinguistics.

Brown, A., \& Gullberg, M. (2010). Changes in the encoding of motion in a first language during acquisition of a second language. Cognitive Linguistics, 21, 263-286. doi:

\subsection{5/COGL.2010.010}

Brown, A., \& Gullberg, M. (2012). Multicompetence and native speaker variation in clausal packaging in Japanese. Second Language Research, 28, 415-442. doi: 10.1177/026765831245582

Cadierno, T. (2004). Expressing motion events in a second language. In M. Achard \& S. Neimeier (Eds.), Cognitive linguistics, second language acquisition and foreign language teaching (pp. 13-49). Berlin: Mouton de Gruyter.

Cadierno, T. (2008). Learning to talk about motion in a foreign language. In P. Robinson \& N. C. Ellis (Eds.), Handbook of cognitive linguistics and second language acquisition (pp. 237-275). New York: Routledge.

Council of Europe (2001). Common European Framework of Reference for Languages: Learning, Teaching and Assessment. Cambridge: Cambridge University Press.

Ellis, N. C. (2008). Usage-based and form-focused acquisition: The associative learning of constructions, learned-attention, and the limited L2 endstate. In P. Robinson \& N. C. Ellis (Eds.), Handbook of cognitive linguistics and second language acquisition (pp. 372-405). London:

Routledge.

Ellis, N. C., \& Cadierno, T. (2009). Constructing a second language: Introduction to the special section. Annual Review of Cognitive Linguistics, 7, 111-139. DOI 10.1075/arcl.7.05ell 
Evans, N. (2011). Semantic typology. In J. J. Song (Ed.), The Oxford handbook of linguistic typology (pp. 504-533). Oxford: Oxford University Press.

Gullberg, M. (2009a). Reconstructing verb meaning in a second language: How English speakers of L2 Dutch talk and gesture about placement. Annual Review of Cognitive Linguistics, 7, 222-245. doi:10.1075/arcl.7.09gul.

Gullberg, M. (2009b). Gestures and the development of semantic representations in first and second language acquisition. AILE Lia 1, 117-139.

Gullberg, M. (2011a). Language-specific encoding of placement events in gestures. In J. Bohnemeyer \& E. Pederson (Eds.), Event representation in language and cognition (pp. 166-188). Cambridge, MA: Cambridge University Press.

Gullberg, M. (2011b). Thinking, speaking and gesturing about motion in more than one language. In A. Pavlenko (Ed.), Thinking and speaking in two languages (pp. 143-169). Clevedon, UK: Multilingual Matters.

Gullberg, M., \& Burenhult, N. (2012). Probing the linguistic encoding of placement and removal events in Swedish. In A. Kopecka \& B. Narasimhan (Eds.), Events of putting and taking: A crosslinguistic perspective (pp. 167-182). Amsterdam: John Benjamins.

Gullberg, M., \& Narasimham, B. (2010). What gestures reveal about how semantic distinctions develop in Dutch children's placement verbs. Cognitive Linguistics, 21, 239-262. doi:10.1515/COGL.2010.009

Hickmann, M. (2007). Static and dynamic location in French: Developmental and cross-linguistic perspectives. In M. Aurnague, M. Hickman, \& L. Vieu (Eds.), Spatial entities in language and cognition (pp. 205-231). Amsterdam: John Benjamins. 
Hickmann, M., \& Hendriks, H. (2006). Static and dynamic location in French and in English. First Language, 26, 103-135. doi: 10.1177/0142723706060743

Hijazo-Gascón, A., \& Ibarretxe-Antuñano, I. (2013). Las lenguas románicas y la tipología de los eventos de movimiento. Romanische Forschungen, 125, 467-494. doi: $10.3196 / 003581213808754483$

Hijazo-Gascón, A., Cadierno, T., \& Ibarretxe-Antuñano, I. (Forthcoming). Learning the caused motion construction in L2 Spanish. In S. De Knop \& G. Gilquin (Eds.), Constructionist approaches to second language acquisition and foreign language teaching. Berlin: Mouton de Gruyter.

Ibarretxe-Antuñano, I. (2004). Language typologies in our language use: the case of Basque motion events in adult oral narratives. Cognitive Linguistics, 15, 317-349. doi:10.1515/cogl.2004.012 Ibarretxe-Antuñano, I. (2009). Path salience in motion events. In J. Guo, E. Lieven, N. Budwig, S. Ervin-Tripp, K. Nakamura, \& S. Özçalışkan (Eds.), Crosslinguistic approaches to the psychology of language: Research in the tradition of Dan Isaac Slobin (pp. 403-414). New York: Psychology Press.

Ibarretxe-Antuñano, I. (2012). Placement and removal events in Basque and Spanish. In A. Kopecka \& B. Narasimhan (Eds.), Events of putting and taking: A crosslinguistic perspective (pp. 123-143). Amsterdam: John Benjamins.

Ibarretxe-Antuñano, I., Cadierno, T., \& Hijazo-Gascón, A. (In press). The role of force dynamics and intentionality in the reconstruction of L2 verb meanings: A Danish-Spanish bidirectional study. Review of Cognitive Linguistics.

Ijaz, H. (1986). Linguistic and cognitive determinants of lexical acquisition in a second language. Language Learning, 36, 401-451. doi: 10.1111/j.1467-1770.1986.tb01034.x

Jackendoff, R. (1990). Semantic structures. Cambridge, MA: The MIT Press. 
Jessen, M., \& Cadierno, T. (2013). Variation in the categorization of motion events by Danish, German, Turkish, and L2 Danish speakers. In J. Goschler \& A. Stefanowitsch (Eds.), Variation and change in the encoding of motion events (pp. 133-160). Amsterdam: John Benjamins.

Kellerman, E. (1995). Crosslinguistic influence: Transfer to nowhere? Annual Review of Applied Linguistics, 15, 125-150. doi: 10.1017/S0267190500002658

Kopecka, A., \& Narasimhan, B. (Eds.). (2012). Events of putting and taking: A crosslinguistic perspective. Amsterdam: John Benjamins.

Levinson, S. C. (2012). Preface. In A. Kopecka \& B. Narasimham (Eds.), Events of putting and taking: A crosslinguistic perspective (pp. xi-xv). Amsterdam: John Benjamins.

Majid, A., Gullberg, M., van Staden, M., \& Bowerman, M. (2007). How similar are semantic categories in closely related languages? A comparison of cutting and breaking in four Germanic languages. Cognitive Linguistics, 12, 179-194. doi:10.1515/COG.2007.007

Majid, A., Boster, J. S., \& Bowerman, M. (2008). The cross-linguistic categorization of everyday events: A study of cutting and breaking. Cognition, 109, 235-250. doi:10.1016/j.cognition.2008.08.009

Malt, B. C., \& Sloman, S. A. (2003). Linguistic diversity and object naming by non-native speakers of English. Bilingualism: Language and Cognition, 6, 47-67. doi:10.1017/S1366728903001020

Malt, B. C., Gennari, S., Imai, M., Ameel, E., Tsuda, N., \& Majid, A. (2008). Talking about walking: Biomechanics and the language of locomotion. Psychological Science, 19, 232-240. doi:10.1111/j.1467-9280.2008.02074.x

Malt, B. C., Ameel, E., Imai, M., Gennari, S. P., Saji, N., \& Majid, A. (2014). Human locomotion in languages: Constraints on moving and meaning. Journal of Memory and Language, 74, 107-123. 
Malt, B. C., \& Majid, A. (2013). How thought is mapped into words. Wiley Interdisciplinary Reviews: Cognitive Science, 4, 583-597. doi: 10.1002/wcs.1251

Narasimhan, B., \& Gullberg, M. (2011). The role of input frequency and semantic transparency in the acquisition of verb meaning: evidence from placement verbs in Tamil and Dutch. Journal of Child Language, 38, 504-532. doi:10.1017/S0305000910000164

Robinson, P., \& Ellis, N. C. (2008). Conclusion: Cognitive linguistics, second language acquisition and L2 instruction - issues for research. In P. Robinson \& N. C. Ellis (Eds.), Handbook of cognitive linguistics and second language acquisition (pp. 489-545). New York: Routledge.

Ruppenhofer, J., Ellsworth, M., Petruck, M. R. L., Johnson, C. R., \& Scheffczyk, J. (2010). FrameNet II: Extended Theory and Practice. https://framenet.icsi.berkeley.edu/fndrupal/the_book. Accessed 13 January 2015.

Saji, N., \& Imai, M. (2013). Evolution of verb meanings in children and L2 adult learners through reorganization of an entire semantic domain: The case of Chinese carry/hold verbs. Scientific Studies of Reading, 17, 71-88.

Saji, N., Imai, M., Saalbach, H., Zhang, Y., Shu, H., \& Okada, H. (2011). Word learning does not end at fast-mapping: Evolution of verb meanings through reorganization of an entire semantic domain. Cognition, 118, 45-61. doi: 10.1016/j.cognition.2010.09.007

Simpson, E. H. (1949). Measurement of diversity. Nature, 163, 688. doi:10.1038/163688a0

Slobin, D. I., Bowerman, M., Brown, P., Eissenbeiß, S., \& Narasimhan, B. (2011). Putting things in places. In J. Bohnemeyer \& E. Pederson (Eds), Event representation in language and cognition (pp. 134-165). Cambridge: Cambridge University Press. 
Slobin, D. I., Ibarretxe-Antuñano, I., Kopecka, A., \& Majid, A. (2014). Manners of human gait: A crosslinguistic event-naming study. Cognitive Linguistics, 25, 701-741. doi:10.1515/cog-20140061

Stockwell, R., Brown, J., \& Martin, J. (1965). The grammatical structures of English and Spanish. Chicago: Chicago University Press.

Talmy, L. (1985). Lexicalization patterns: Semantic structure in lexical forms. In T. Shopen (Ed), Language typology and semantic description, Volume 3: Grammatical categories and the lexicon (pp. 36-149). Cambridge: Cambridge University Press.

Talmy, L. (2000). Toward a cognitive semantics, Volume II: Typology and process in concept structuring. Cambridge, MA: The MIT Press.

Viberg, Å. (1998). Crosslinguistic perspectives on lexical acquisition: The case of language-specific semantic differentiation. In K. Haastrup \& Å. Viberg (Eds.), Perspectives on lexical acquisition in a second language (pp. 175-208). Lund: Lund University Press.

\section{Supporting Information}

Additional Supporting Information may be found in the online version of this article at the publisher's website:

Appendix S1. Description of CEFR Proficiency Levels.

Appendix S2. Description of Video Clips Used in This Study.

Appendix S3. Simpson's Diversity Index.

Appendix S4. Cluster Analysis.

Appendix S5. List of Verbs Used by the Four Participant Groups. 
Appendix S6. Use of Some Danish Verbs in Corpora.

Appendix S7. Breakdown of Verbs Used Per Video Clip Within Each Cluster. 
Table 1 Mean values for verb tokens, types, type-token ratios, and Simpson Diversity Index in the four participant groups

\begin{tabular}{lcccc}
\hline Group & Tokens & Types & Type-token ratios [95\% CI $]$ & D [95\% CI] \\
\hline L1 Spanish & 30.9 & 12.50 & $0.40[0.37-0.44]$ & $0.56[0.48-0.64]$ \\
L1 Danish & 31.0 & 12.86 & $0.41[0.39-0.44]$ & $0.57[0.48-0.67]$ \\
L2 Spanish & 28.0 & 6.71 & $0.25[0.20-0.30]$ & $0.32[0.27-0.37]$ \\
L2 Danish & 29.7 & 8.29 & $0.28[0.24-0.31]$ & $0.24[0.18-0.30]$ \\
\hline
\end{tabular}

Note. $\mathrm{CI}=$ confidence intervals. 
Table 2 Summary of the main verbs used for Danish and Spanish semantic categories

\begin{tabular}{|c|c|c|c|c|c|c|}
\hline \multirow{3}{*}{ 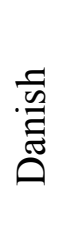 } & \multicolumn{2}{|c|}{ Support } & \multicolumn{4}{|c|}{ Containment } \\
\hline & Horizontal & Vertical & Partial & Full horizontal & Full tight-fit & Full general \\
\hline & loegge "lay" & scette/stille"set" & scette "set" & loegge "lay" & stikke "stick" & putte "put (in)" \\
\hline \multirow{3}{*}{ 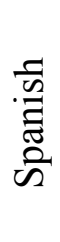 } & \multirow{2}{*}{\multicolumn{2}{|c|}{ Support }} & \multicolumn{4}{|c|}{ Containment } \\
\hline & & & \multicolumn{2}{|c|}{ Partial } & \multicolumn{2}{|l|}{ Full } \\
\hline & \multicolumn{2}{|c|}{ dejar "leave (in a place)" } & \multicolumn{2}{|c|}{ poner "put" } & \multicolumn{2}{|c|}{ meter "put in" } \\
\hline
\end{tabular}




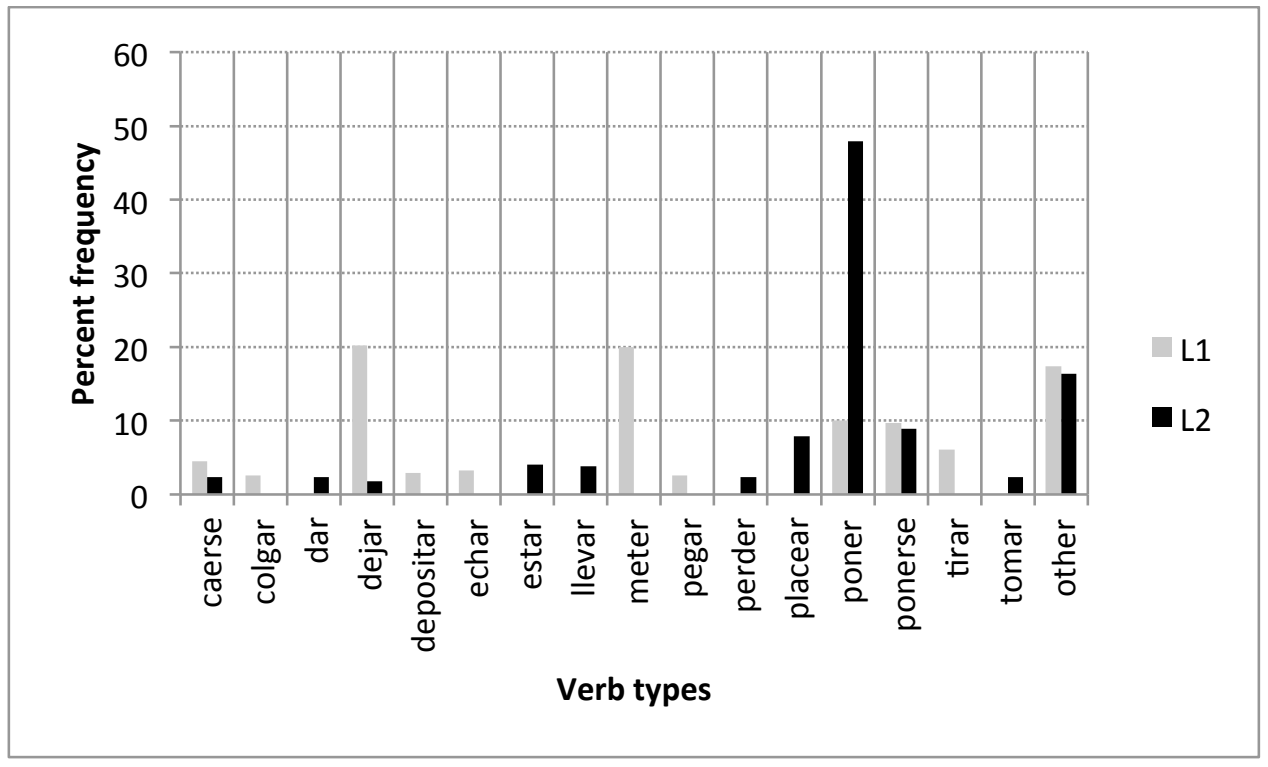

Figure 1 Verbs used by L1 and L2 Spanish speakers. 


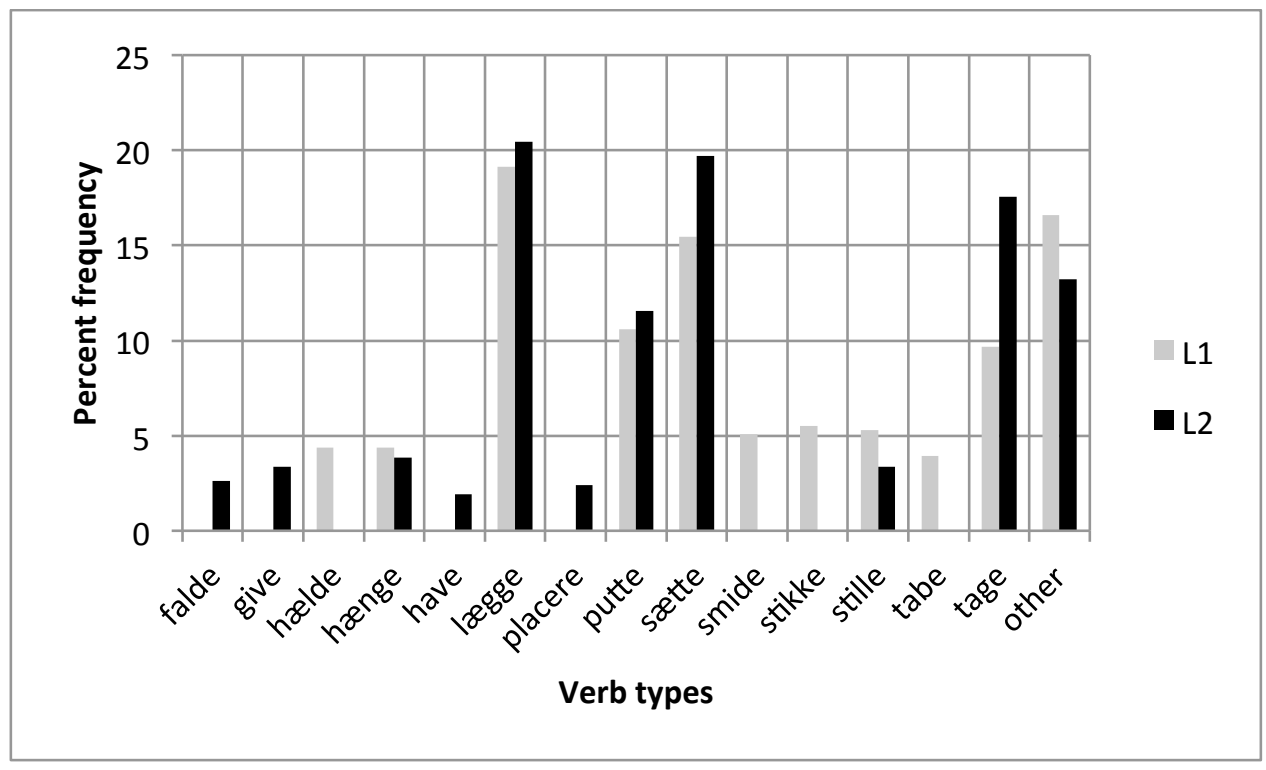

Figure 2 Verbs used by L1 and L2 Danish speakers. 


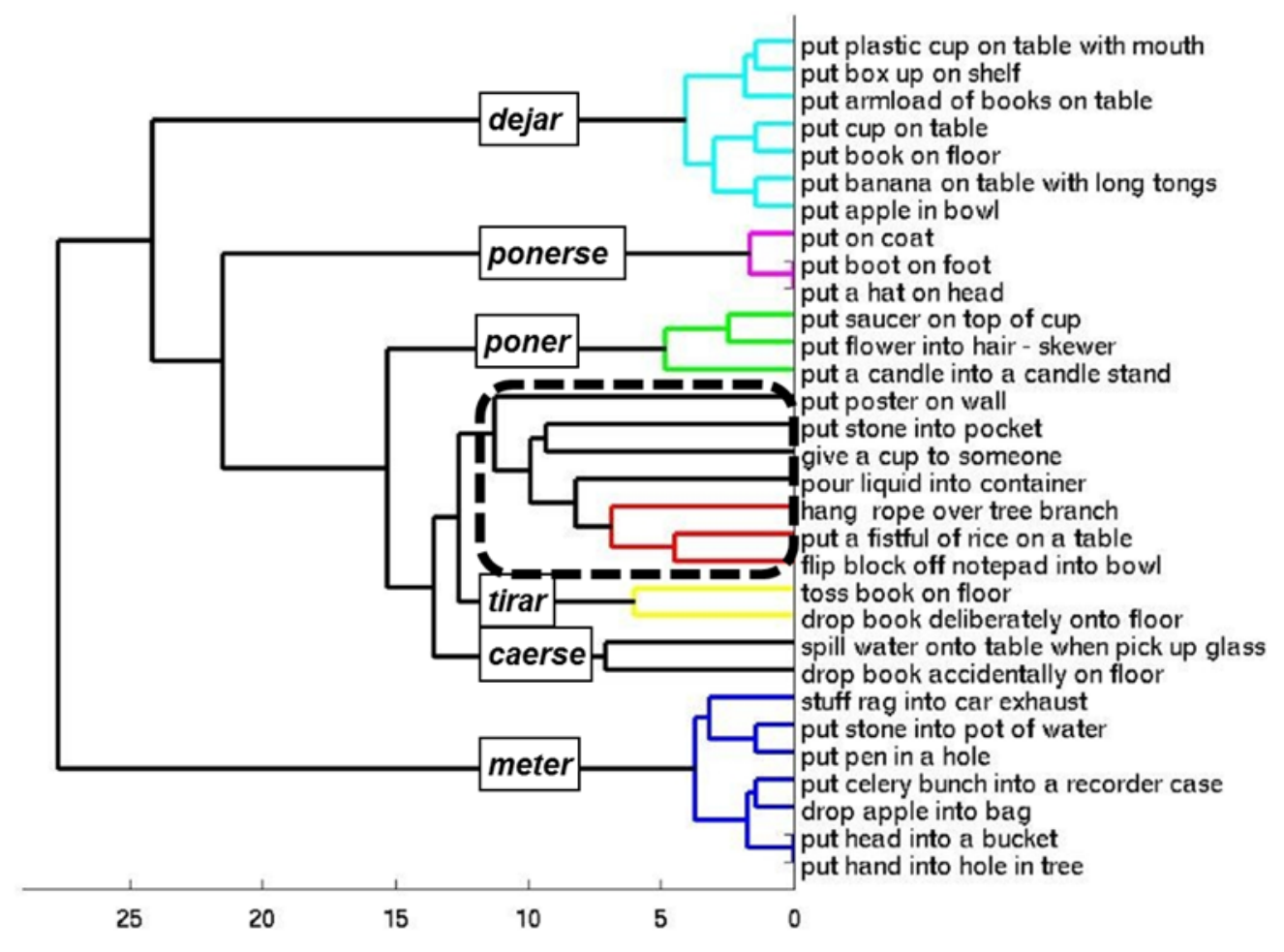

Figure 3 Cluster dendrogram for L1 Spanish. 


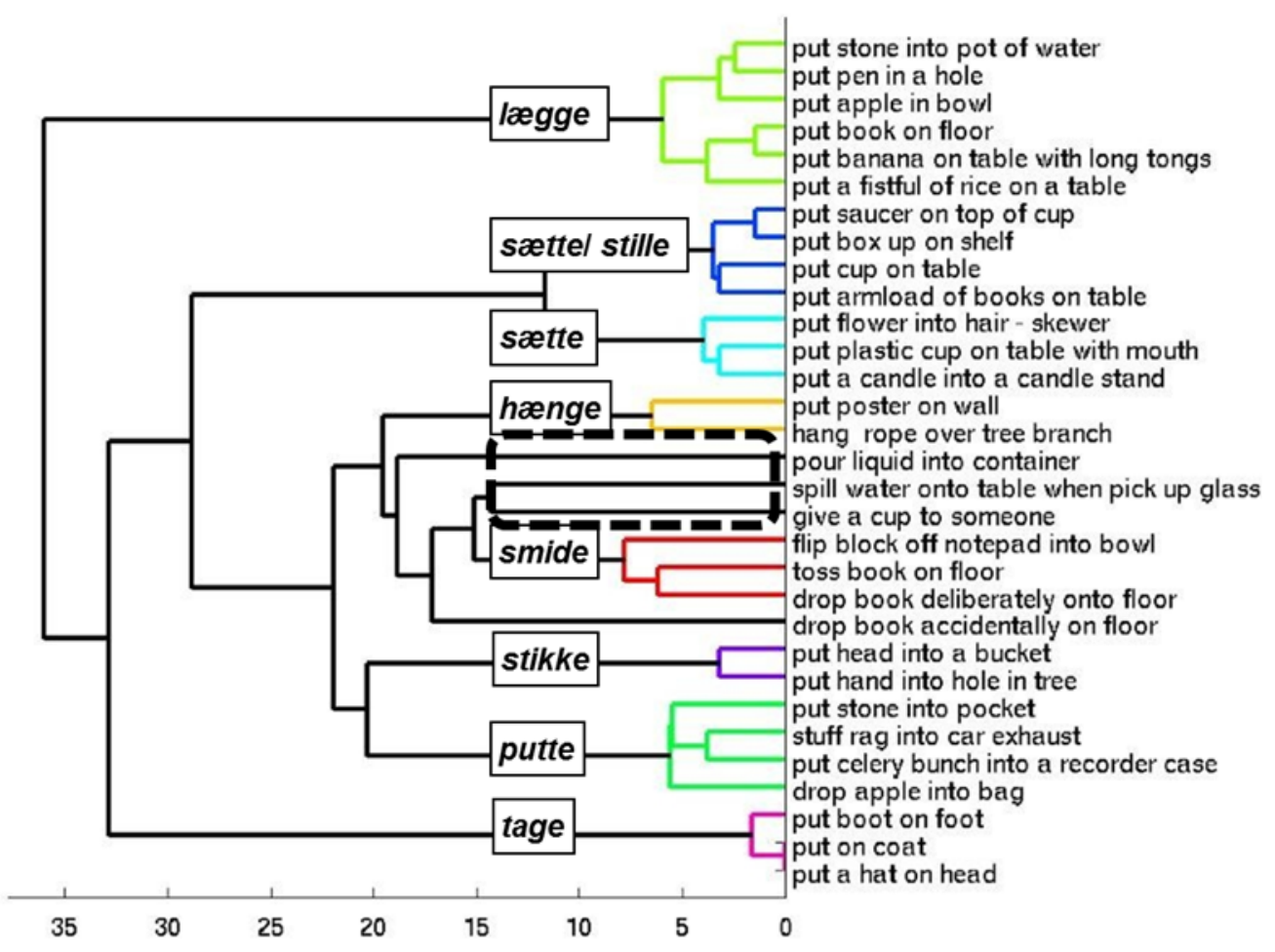

Figure 4 Cluster dendrogram for L1 Danish. 


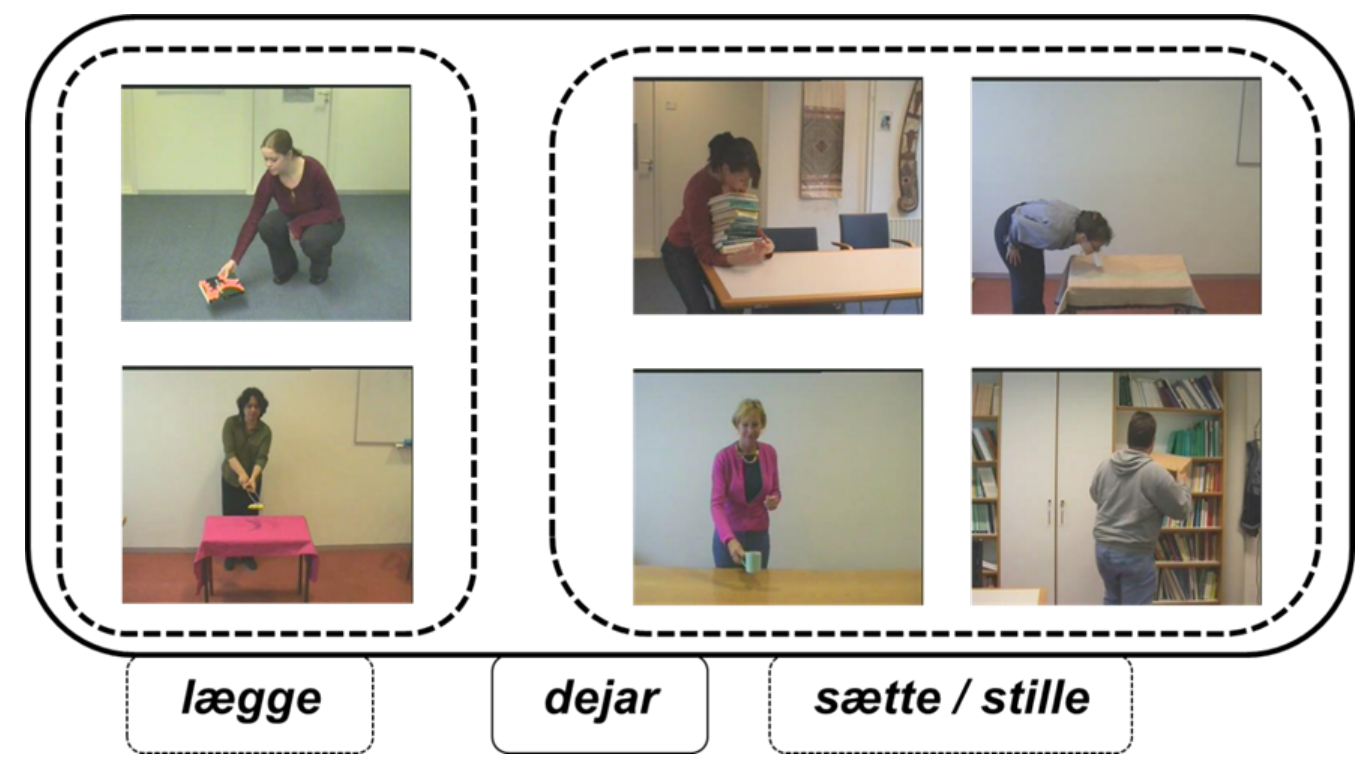

Figure 5 Different semantic categories for support in Spanish (dejar) and Danish (loegge, satte/stille). Images adapted from Bowerman et al. (2004). 


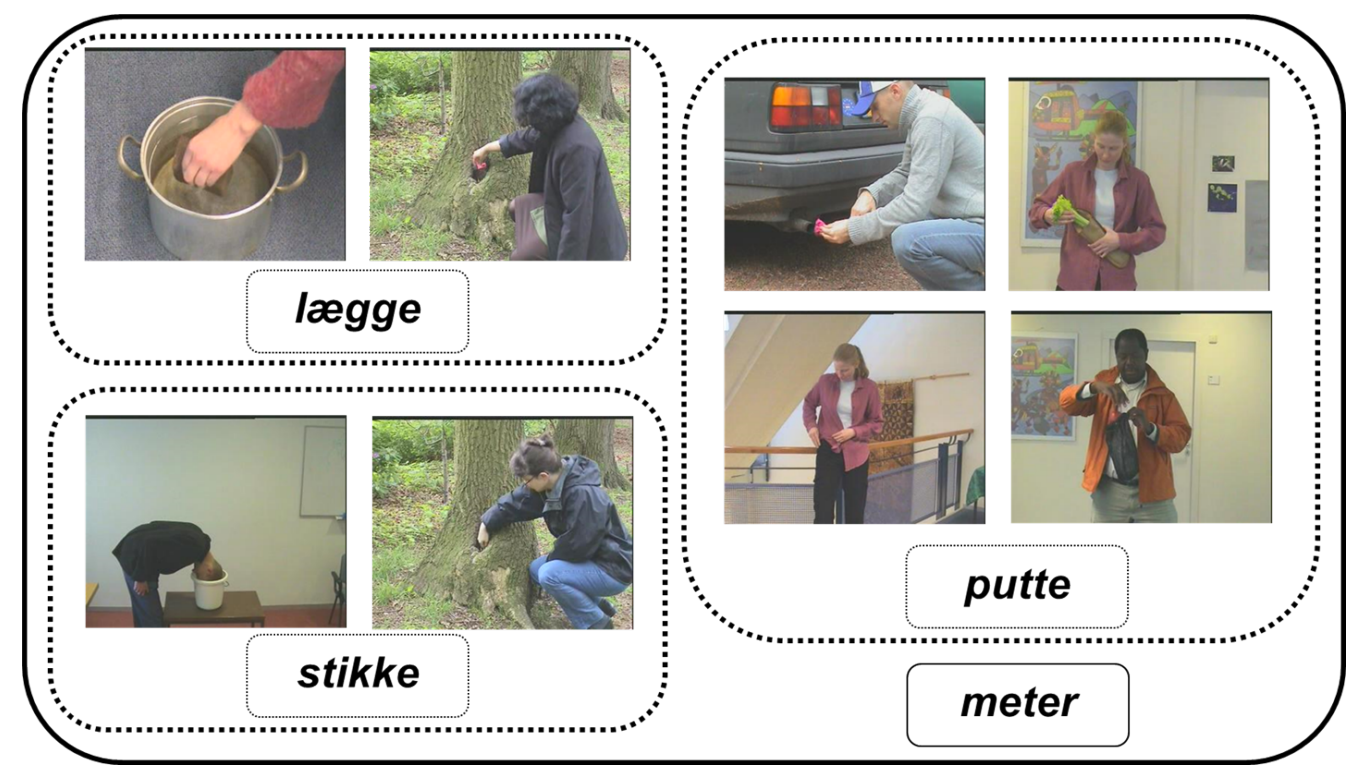

Figure 6 Different semantic categories for containment in Spanish (meter) and Danish (lagge, stikke, putte). Images adapted from Bowerman et al. (2004). 


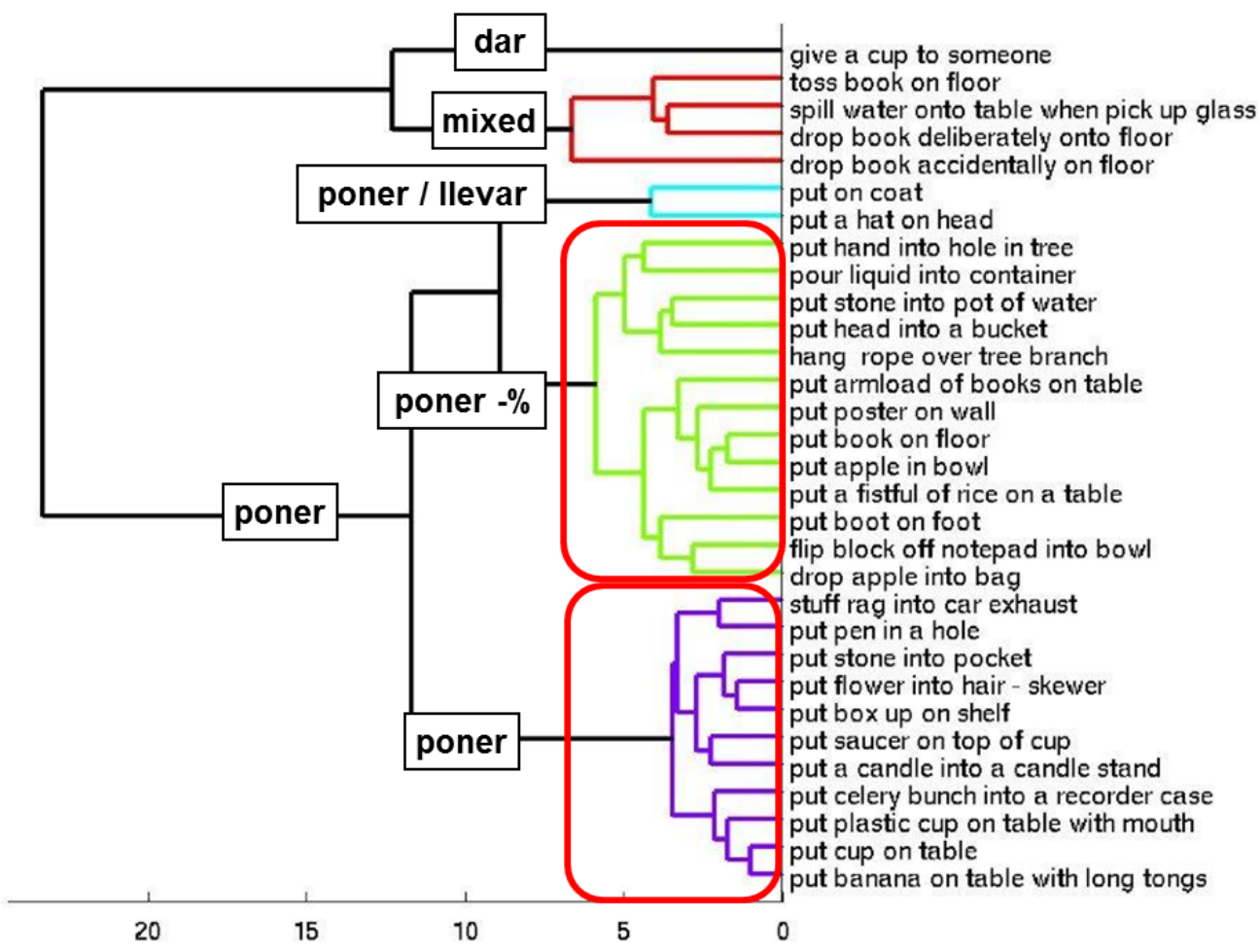

Figure 7 Cluster dendrogram for L2 Spanish. 


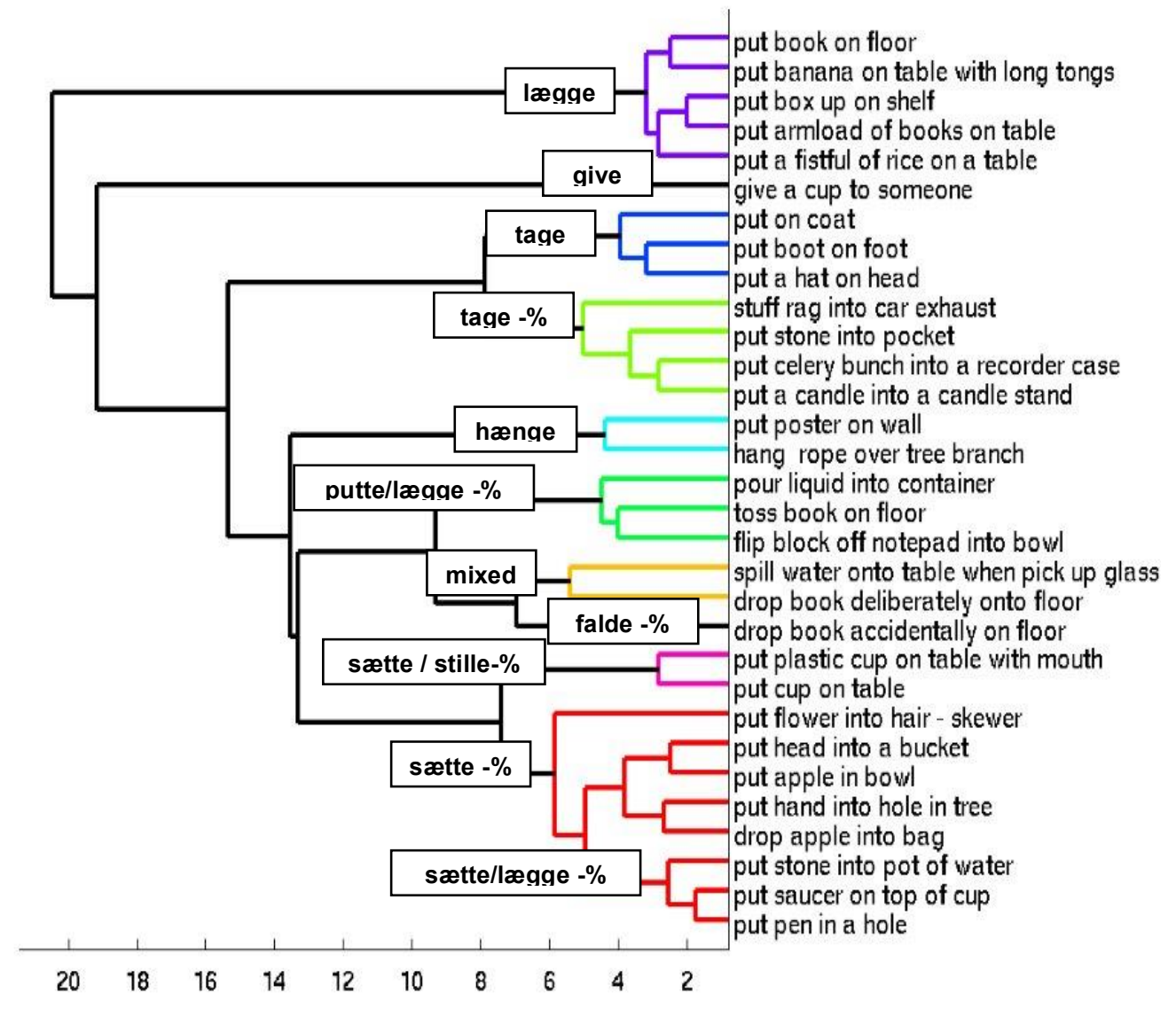

Figure 8 Cluster dendrogram for L2 Danish. 

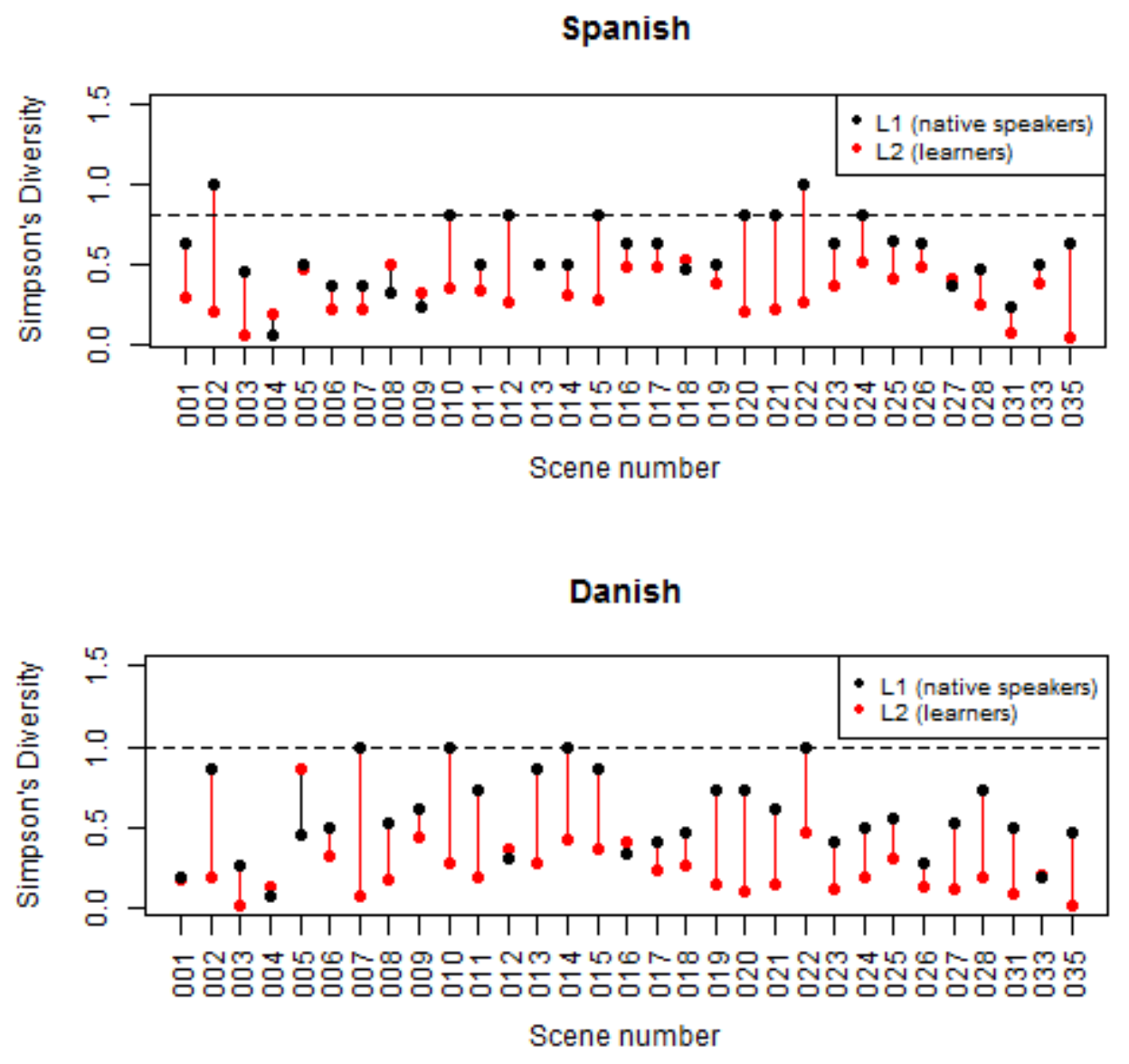

Figure 9 Simpson's Diversity Index for each language and each scene. 

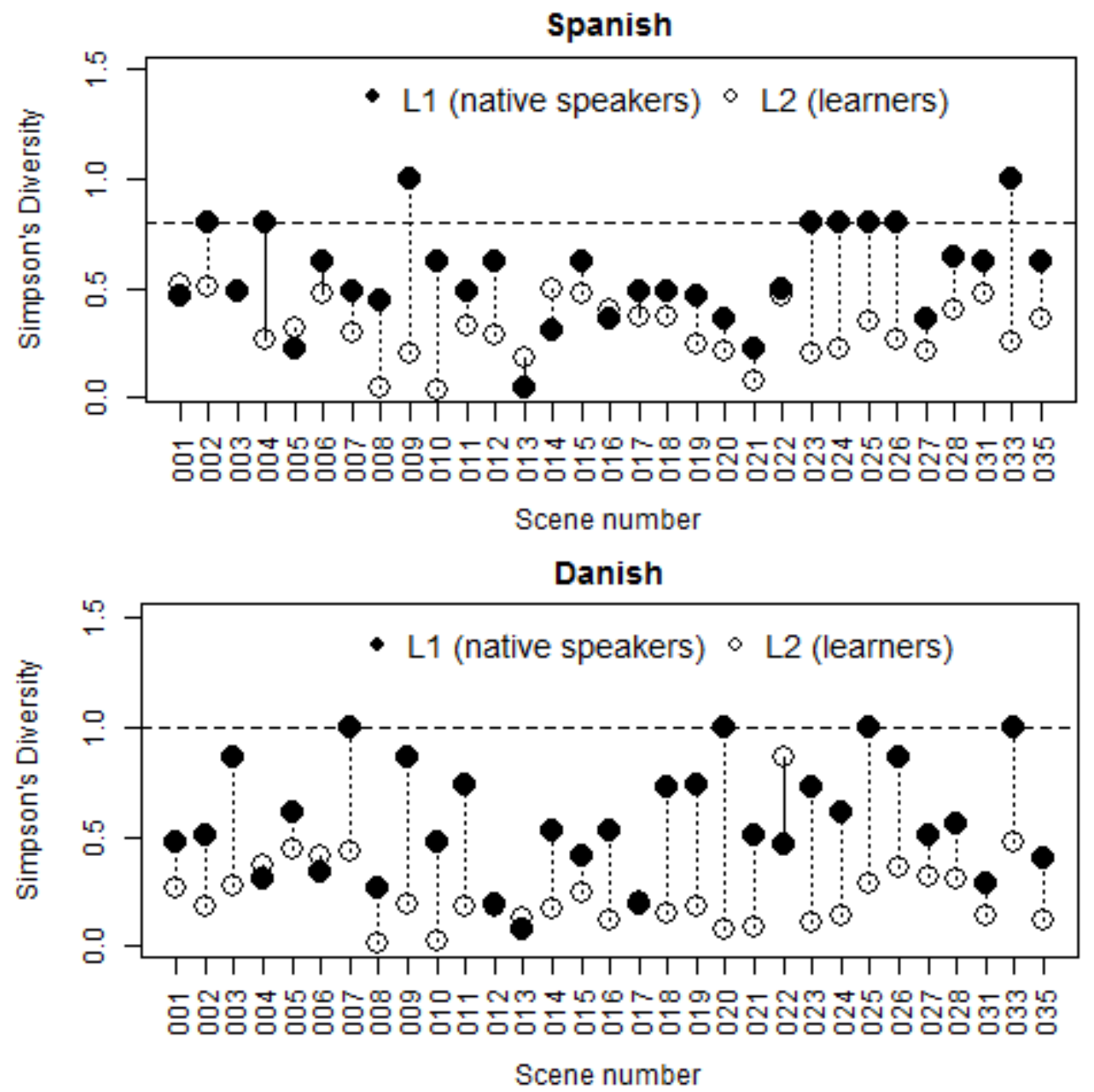

Figure 9 Simpson's Diversity Index for each language and each scene. 